\title{
Association study between matrix metalloproteinase-9 gene (MMP9) polymorphisms and the risk of Henoch-Schönlein purpura in children
}

\author{
E.D. Xu' ${ }^{1}$, Y.F. Xiao ${ }^{1}$, J.J. Wang ${ }^{1}$ and L. Dong ${ }^{2}$ \\ ${ }^{1}$ Department of Pediatrics, \\ The Second Affiliated Hospital of Xi' an Jiaotong University, Xi'an, China \\ ${ }^{2}$ Department of Gastroenterology, \\ The Second Affiliated Hospital of Xi' an Jiaotong University, Xi'an, China \\ Corresponding author: L. Dong \\ E-mail: duanchanghongys@163.com
}

Genet. Mol. Res. 15 (2): gmr.15028095

Received November 18, 2015

Accepted February 11, 2015

Published June 3, 2016

DOI http://dx.doi.org/10.4238/gmr.15028095

\begin{abstract}
Henoch-Schönlein purpura nephritis (HSPN), the most serious long-term complication of Henoch-Schönlein purpura, is one of the most common renal diseases in children. Matrix metalloproteinase- 9 (MMP-9) is implicated in the pathogenesis of renal diseases. Genomic DNA was isolated from the venous blood leukocytes of 220 unrelated patients with HSPN and 205 unrelated healthy individuals. To identify markers contributing to genetic susceptibility to HSPN, this study examined the potential association between HSPN and four single nucleotide polymorphisms of the MMP-9 gene (MMP9) (rs17576, rs3918254, rs3787268, and rs2236416) by using the MassARRAY system. The allelic or genotypic frequencies of the rs 17576 (exon 6) and rs3918254 (intron 6) polymorphisms in HSPN were significantly different from those in the healthy controls. The HSPN subjects had a significantly higher frequency of the $\mathrm{G}$ allele of $\operatorname{rs} 17576\left(\chi^{2}=8.416, \mathrm{P}\right.$
\end{abstract}


$=0.004, \mathrm{OR}=1.556,95 \% \mathrm{CI}=1.153-2.100)$ and a significantly lower frequency of the A allele of rs2236416 $\left(\chi^{2}=10.363, \mathrm{P}=0.001, \mathrm{OR}=\right.$ $0.545,95 \% \mathrm{CI}=0.375-0.791)$. Linkage disequilibrium was observed in two blocks ( $\mathrm{D}^{\prime}>0.9 ; \mathrm{r}^{2}>0.8$ in control). In block 1 , significantly more G-C haplotypes $(\mathrm{P}=0.011)$ and significantly fewer $\mathrm{A}-\mathrm{C}$ haplotypes $(\mathrm{P}=$ 0.008 ) were found in the HSPN subjects. In block 2 , significantly more G-G haplotypes $(P=0.016)$ and significantly fewer A-G haplotypes $(\mathrm{P}=0.006)$ were found in the HSPN subjects. These observations suggest that the rs17576 and rs3918254 polymorphisms of $M M P 9$ are associated with HSPN.

Key words: Henoch-Schönlein purpura nephritis; Matrix metalloproteinase-9; Single nucleotide polymorphisms

\section{INTRODUCTION}

Henoch-Schönlein purpura (HSP) is one of the most common vasculitides in children. Manifestations of HSP include skin purpura, arthritis, abdominal pain, and renal involvement (Chen and Mao, 2015). The severity of renal involvement is the major factor determining the long-term outcome for children with HSP and Henoch-Schönlein purpura nephritis (HSPN). Approximately 40\% of children with HSP develop nephritis, usually within 4-6 weeks after the initial onset of typical purpuric rashes. It has been found that levels of matrix metalloproteinase-9 (MMP-9) and tissue inhibitor of metalloproteinases-1 (TIMP-1), and the ratio of MMP-9 to TIMP-1 in the serum and urine are notably higher in patients with HSPN, but serum MMP-9 is more sensitive. Therefore, serum MMP-9 may be associated with the occurrence and development of renal involvement in HSPN, making it an important indicator for early diagnosis of HSPN (Qin et al., 2011). Considering the racial diversity and clinical heterogeneity of subjects, genetic factors might play a role in the pathogenesis of HSP and HSPN (Yilmaz et al., 2009; Li and Liu, 2011; Zhou and Yin, 2013).

In the last decade MMPs have been reported to be the most important proteolytic enzymes involved in remodeling the extracellular matrix. They are also crucial for tissue development and homeostasis. In human beings, MMP-9, an enzyme of the MMP family that is also known as gelatinase $\mathrm{B}$ or $92-\mathrm{kDa}$-type IV collagenase, is encoded by the $M M P 9$ gene. In vascular lesions, the disintegration of arterial elastic lamella and basement membranes by proteolytic enzymes may play an important role in arterial stability, excessive cell migration, and proliferation (Raffetto and Khalil, 2008). The $M M P 9$ gene is involved in the pathogenesis of inflammatory vascular diseases (Nikkari et al., 1996; Takeshita et al., 2001). Therefore, because it plays a pivotal role in facilitating the extravasation and migration of leukocytes by breaking down the basement membrane, it is suggested that this gene contributes to the pathogenesis of HSP and HSPN.

$M M P 9$ has the chromosomal locus 20q12.2-13.1. Single nucleotide polymorphisms (SNPs) have been described in MMP9. Previous studies have shown that the $-1562 \mathrm{C} / \mathrm{T}$ polymorphism in the promoter region of the human $M M P 9$ gene is associated with MMP-9 protein activity (Medley et al., 2004). In human aortic samples, MMP-9 mRNA and protein expression were significantly higher in T allele carriers (Medley et al., 2004). However, the relationship between genetic susceptibility to HSPN and MMP9 gene has not yet been 
investigated. Because of the limited weak linkage disequilibrium (LD) between SNPs in $M M P 9$, it has been hypothesized that there may not be true causality between the SNPs and predisposition to the development of HSPN; therefore, we hypothesized that the common variants in the $M M P 9$ gene might contribute more significantly to this predisposition. In the present study, we investigated the association between four SNPs of the MMP9 gene (rs17576, rs3918254, rs3787268, and rs2236416) and the risk of HSPN in a Chinese population by comparing the allele frequencies and genotypes of 220 patients with HSPN and 205 healthy controls.

\section{MATERIAL AND METHODS}

\section{Subjects}

A total of 220 unrelated subjects with HSPN (mean age $7.26 \pm 2.51$ years) were recruited from The Second Affiliated Hospital of Xi'an Jiaotong University. HSP was diagnosed if the major manifestations of the illness consisted of a purpuric rash without thrombocytopenia. Additional features including arthritis and abdominal pain were accepted as being consistent with the diagnosis (Kawasaki et al., 2003; Reamy et al., 2009). HSPN was defined by abnormal urinalysis results in HSP patients and categorized as follows: normal levels of proteinuria (proteinuria $<0.5 \mathrm{~g} / \mathrm{L}$ and hematuria $\geq 5$ red blood cells per high-power microscopic field); low-grade proteinuria $(<1 \mathrm{~g} / \mathrm{L}$ and/or hematuria $\geq 5$ red blood cells per highpower microscopic field); and heavy proteinuria ( $\geq 1 \mathrm{~g} / \mathrm{L}$ and/or hematuria $\geq 5 \mathrm{red}$ blood cells per high-power microscopic field) (Hung et al., 2006; de Almeida et al., 2007). The control group included 204 unrelated healthy people (mean age $6.75 \pm 2.36$ years) recruited from the medical examination center of our hospital. All participants were genetically unrelated, of Han Chinese ethnicity, and from Henan Province. The study complied with the guidelines of our local Medical Ethics Committee, and all participants recruited to this study provided written informed consent.

\section{Genotyping}

Peripheral blood (3-5 mL) was collected from each participant and placed in ethylenediaminetetraacetic acid-containing specimen tubes. Genomic DNA was extracted using a TIANamp Blood DNA Kit (TIANGEN, Beijing, China) and then stored at $-20^{\circ} \mathrm{C}$ until required. SNP genotyping was performed using matrix-assisted laser desorption ionizationtime of flight mass spectrometry (MALDI-TOF MS) (MassARRAY system, Sequenom Inc., San Diego, CA, USA). Primers were designed using the Sequenom software, and the extension reaction produced allele-specific products with masses differing by $30 \mathrm{Da}$, or approximately the size of one single nucleotide. Primer extension and polymerase chain reaction (PCR) were performed according to the manufacturer instructions. Genotype calling was performed in real-time using the MassARRAY RT software version 3.0.0.4 and data analysis was performed using the MassARRAY Typer software version 3.4 (Sequenom Inc.).

\section{Statistical analysis}

Allele and genotype frequencies for each individual polymorphism and the Hardy- 
Weinberg equilibrium were evaluated using the chi-square test. Potential association between HSPN and each polymorphism was analyzed using Fisher exact test or the Pearson chisquare test. All statistical analyses were performed using SPSS 20.0 with $\mathrm{P}<0.05$ denoting statistically significant difference. Pairwise LD statistics ( $\mathrm{D}^{\prime}$ and $\mathrm{r}^{2}$ ) and haplotype frequency were computed using Haploview 4.0 to construct haplotype blocks.

\section{RESULTS}

The genotype distribution of the three polymorphisms was consistent with the HardyWeinberg equilibrium. The distribution of genotype and allele frequencies and statistical analysis of the three SNPs are listed in Table 1.

Table 1. Genotypic and allelic frequencies of MMP-9 polymorphisms in the controls and patients with Henoch-Schönlein purpura in children.

\begin{tabular}{|c|c|c|c|c|c|c|}
\hline \multirow[t]{2}{*}{ Variable } & \multicolumn{2}{|c|}{ Controls } & \multicolumn{2}{|c|}{ Henoch-Schönlein purpura in children } & \multirow[t]{2}{*}{$\chi^{2}, \mathrm{P}_{\text {value }}{ }^{\mathrm{a}}$} & \multirow[t]{2}{*}{ OR $(95 \% \mathrm{CI})$} \\
\hline & No. & $\%$ & No. & $\%$ & & \\
\hline \multicolumn{7}{|l|}{ rs17576 } \\
\hline $\mathrm{G} / \mathrm{G}$ & 93 & 45.59 & 123 & 55.91 & \multirow[t]{3}{*}{$8.291,0.016$} & \\
\hline $\mathrm{A} / \mathrm{G}$ & 86 & 42.16 & 87 & 39.55 & & \\
\hline $\mathrm{A} / \mathrm{A}$ & 25 & 12.25 & 10 & 4.55 & & \\
\hline G & 272 & 66.67 & 333 & 75.68 & \multirow[t]{2}{*}{$8.416,0.004$} & \multirow[t]{2}{*}{$1.556(1.153-2.100)$} \\
\hline $\mathrm{A}$ & 136 & 33.33 & 107 & 24.32 & & \\
\hline \multicolumn{7}{|c|}{ rs3918254 } \\
\hline $\mathrm{C} / \mathrm{C}$ & 125 & 60.98 & 148 & 67.27 & \multirow[t]{3}{*}{$3.471,0.176$} & \\
\hline $\mathrm{C} / \mathrm{T}$ & 74 & 36.10 & 62 & 28.18 & & \\
\hline$T / T$ & 6 & 2.93 & 10 & 4.55 & & \\
\hline $\mathrm{C}$ & 324 & 79.02 & 358 & 81.36 & \multirow[t]{2}{*}{$0.732,0.392$} & \multirow[t]{2}{*}{$1.159(0.827-1.625)$} \\
\hline $\mathrm{T}$ & 86 & 20.98 & 82 & 18.64 & & \\
\hline \multicolumn{7}{|l|}{ rs 3787268} \\
\hline $\mathrm{G} / \mathrm{G}$ & 88 & 42.93 & 83 & 37.73 & \multirow[t]{3}{*}{$5.748,0.056$} & \\
\hline $\mathrm{A} / \mathrm{G}$ & 97 & 47.32 & 98 & 44.55 & & \\
\hline $\mathrm{A} / \mathrm{A}$ & 20 & 9.76 & 39 & 17.73 & & \\
\hline G & 237 & 66.59 & 264 & 60.00 & \multirow[t]{2}{*}{$0.970,0.325$} & \multirow[t]{2}{*}{$0.867(0.653-1.152)$} \\
\hline A & 137 & 33.41 & 176 & 40.00 & & \\
\hline \multicolumn{7}{|c|}{ rs 2236416} \\
\hline $\mathrm{A} / \mathrm{A}$ & 157 & 76.59 & 136 & 61.82 & \multirow[t]{3}{*}{$10.983,0.004$} & \\
\hline $\mathrm{A} / \mathrm{G}$ & 45 & 21.95 & 77 & 35.00 & & \\
\hline $\mathrm{G} / \mathrm{G}$ & 3 & 1.46 & 7 & 3.18 & & \\
\hline A & 359 & 87.56 & 349 & 79.32 & \multirow[t]{2}{*}{$10.363,0.001$} & \multirow[t]{2}{*}{$0.545(0.375-0.791)$} \\
\hline G & 51 & 12.44 & 91 & 20.68 & & \\
\hline
\end{tabular}

a $\mathrm{P}$ values were calculated by $2 \times 3$ and $2 \times 2$ chi-squared tests based on codominant, dominant for the rare allele, heterosis, and recessive for the rare allele models of inheritance. The alpha value was adjusted by the Bonferroni correction and $\mathrm{P}<0.0125$ indicates statistically significant results.

The allelic and genotypic frequencies of the rs 17576 polymorphisms in patients with HSPN were significantly different from those in the healthy controls. The HSPN subjects had a significantly higher frequency of the $\mathrm{G}$ allele of rs $17576\left(\chi^{2}=8.416, \mathrm{P}=0.004, \mathrm{OR}=\right.$ $1.556,95 \% \mathrm{CI}=1.153-2.100)$. The difference in the distribution of genotype frequencies of rs2236416 between HSPN subjects and healthy controls was significant $(\mathrm{P}=0.0021)$. The HSPN subjects had a significantly lower frequency of the A allele of rs2236416 $\left(\chi^{2}=10.363\right.$, $\mathrm{P}=0.001, \mathrm{OR}=0.545,95 \% \mathrm{CI}=0.375-0.791)$.

LD analyses of the patient and control data revealed that two SNPs (rs17576 and rs3918254) are located in haplotype block 1 and two SNPs (rs2236416 and rs3787268) are located in haplotype block 2 ( $\mathrm{D}^{\prime}>0.9$, Figure 1 ). In block 1 , significantly more G-C haplotypes $(\mathrm{P}=0.011)$ and significantly fewer A-C haplotypes $(\mathrm{P}=0.008)$ were found in the HSPN 
subjects (Table 2$)$. In block 2 , significantly more $\mathrm{G}-\mathrm{G}$ haplotypes $(\mathrm{P}=0.016)$ and significantly fewer A-G haplotypes $(\mathrm{P}=0.006)$ were found in the HSPN subjects (Table 3$)$.

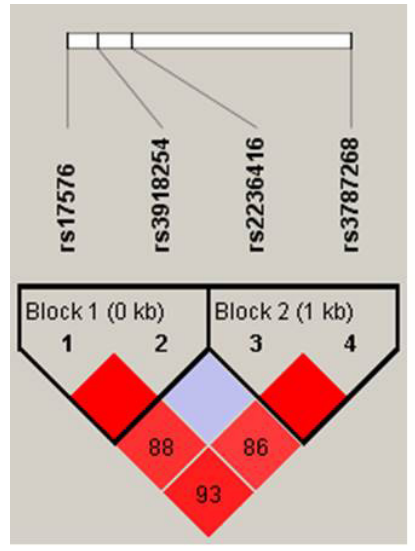

$\mathrm{D}^{\prime}$ in Controls

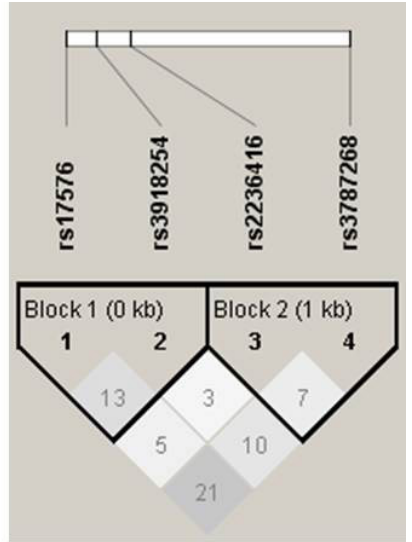

$\mathrm{r}^{2}$ in Controls

Figure 1. Linkage disequilibrium plot of the single nucleotide polymorphisms in the $M M P 1$ gene in the controls.

Table 2. MMP-9 haplotype in block 1 frequencies and the results of their associations with risk of HenochSchönlein purpura in children.

\begin{tabular}{l|c|c|c|c|c}
\hline \multicolumn{2}{l|}{} & \multicolumn{2}{|c|}{ Frequency (\%) $^{*}$ P value $^{\mathrm{a}}$} \\
\hline & rs17576 & rs3918254 & Cases & Controls & \\
\hline HAP1 & G & C & 0.606 & 0.459 & 0.011 \\
\hline HAP2 & A & C & 0.207 & 0.332 & 0.008 \\
\hline HAP2 & G & T & 0.155 & 0.210 & 0.186 \\
\hline
\end{tabular}

${ }^{a}$ Based on comparison of frequency distribution of all haplotypes for the combination of single nucleotide polymorphisms.

Table 3. MMP-9 haplotype in block 2 frequencies and the results of their associations with risk of HenochSchönlein purpura in children.

\begin{tabular}{l|c|c|c|c|c}
\hline \multicolumn{1}{l|}{ Haplotype } & \multicolumn{3}{|c|}{ Frequency (\%) $^{*}$} & \multirow{2}{*}{ P value } \\
\hline & rs2236416 & rs3787268 & Cases & Controls & \\
\hline HAP1 & A & A & 0.369 & 0.334 & 0.335 \\
\hline HAP2 & A & G & 0.397 & 0.541 & 0.006 \\
\hline HAP2 & G & G & 0.203 & 0.124 & 0.016 \\
\hline
\end{tabular}

a Based on comparison of frequency distribution of all haplotypes for the combination of single nucleotide polymorphisms.

\section{DISCUSSION}

Accelerated extracellular matrix breakdown caused by the increased activity of MMPs has been implicated in several rheumatic disorders and systemic vasculitides, especially HSPN. This study demonstrated the upregulated expression of MMP-9 in peripheral blood mononuclear cells, which are an important source of elevated MMP production in the serum of subjects with HSP (Mahajan et al., 2010). Our data are further supported by an isolated 
report by Zou et al. (2006), which indicated that there are increased plasma levels of MMP-9 in children in the acute phase of HSP compared with healthy controls. Our results provide direct evidence that a genetic change in MMP-9 is linked to HSPN in children, and the relevant markers were mapped to different locations in the $M M P 9$ gene. The association signals in the region were identified, and some significantly associated haplotypes also appeared in this region.

In this study, the frequency of the $M M P 9$ rs $17576 \mathrm{G}$ allele was significantly higher in patients with HSPN than in the healthy controls. Genotype frequency distribution revealed that in rs17576 the frequency of the GG genotype was significantly higher in the patients with HSPN. We have also demonstrated that the HSPN subjects had a significantly lower frequency of the $M M P 9$ rs2236416 A allele. Although the precise molecular mechanism underlying our observations is unclear, one possible explanation is that the variants of the $M M P 9$ gene may lead to altered gene expression in HSPN patients. Another important finding in our study was that transcriptional expressions and serum activities of both $M M P-2$ and $M M P-9$ were significantly higher in HSP subjects in the convalescent phase than in healthy controls. Our observations thus strongly suggest that determining levels of $M M P-9$ could be useful in the long-term monitoring of HSPN disease (Mahajan et al., 2010).

We further investigated genetic interactions among polymorphisms and strong LD was observed. The haplotype analysis revealed that significantly more G-C haplotypes (block 1) and G-G haplotypes (block 2) were found in the patients with HSPN. These results indicate that the patients with G-C and G-G haplotypes of the MMP9 gene were more prone to HSPN. We also found significantly fewer A-C haplotypes (block 1) and A-G haplotypes (block 2) in HSPN subjects, suggesting that these haplotypes may protect against HSPN. To some extent, this finding further supports a role of $M M P 9$ polymorphisms in HSPN.

In conclusion, our study suggests a potential role of $M M P 9$ SNPs and their related haplotypes in the genetic susceptibility to HSPN. Further studies are needed to determine how these SNPs affect the function of HSPN.

\section{Conflicts of interest}

The authors declare no conflict of interest.

\section{REFERENCES}

Chen JY and Mao JH (2015). Henoch-Schönlein purpura nephritis in children: incidence, pathogenesis and management. World J. Pediatr. 11: 29-34. http://dx.doi.org/10.1007/s12519-014-0534-5

de Almeida JL, Campos LM, Paim LB, Leone C, et al. (2007). Renal involvement in Henoch-Schönlein purpura: a multivariate analysis of initial prognostic factors. J. Pediatr. 83: 259-266.

Hung SH, Yang YH, Lee CC, Wang LC, et al. (2006). Clinical predictors of self-limited urinalysis abnormality in childhood Henoch-Schönlein purpura nephritis. Acta Paediatr. 95: 306-311. http://dx.doi.org/10.1080/08035250500421584

Kawasaki Y, Suzuki J, Nozawa R, Suzuki S, et al. (2003). Efficacy of methylprednisolone and urokinase pulse therapy for severe Henoch-Schönlein nephritis. Pediatrics 111: 785-789. http://dx.doi.org/10.1542/peds.111.4.785

Li J and Liu H (2011). P-selectin gene -825 polymorphism is associated with risk of Henoch-Schonlein purpura nephritis. Clin. Exp. Rheumatol. 29 (Suppl 64): S134.

Mahajan N, Bisht D, Dhawan V, Singh S, et al. (2010). Transcriptional expression and gelatinolytic activity of matrix metalloproteinases in Henoch-Schonlein purpura. Acta Paediatr. 99: 1248-1252. http://dx.doi.org/10.1111/j.16512227.2010.01781.x

Medley TL, Cole TJ, Dart AM, Gatzka CD, et al. (2004). Matrix metalloproteinase-9 genotype influences large artery stiffness through effects on aortic gene and protein expression. Arterioscler. Thromb. Vasc. Biol. 24: 1479-1484. http://dx.doi.org/10.1161/01.ATV.0000135656.49158.95 
Nikkari ST, Höyhtyä M, Isola J and Nikkari T (1996). Macrophages contain 92-kd gelatinase (MMP-9) at the site of degenerated internal elastic lamina in temporal arteritis. Am. J. Pathol. 149: 1427-1433.

Qin YH, Zhou TB, Lei FY, Huang WF, et al. (2011). Cut-off values for serum matrix metalloproteinase-9: is there a threshold to predict renal involvement for Henoch-Schonlein purpura in children? Nephrology 16: 93-99. http:// dx.doi.org/10.1111/j.1440-1797.2010.01360.x

Raffetto JD and Khalil RA (2008). Matrix metalloproteinases and their inhibitors in vascular remodeling and vascular disease. Biochem. Pharmacol. 75: 346-359. http://dx.doi.org/10.1016/j.bcp.2007.07.004

Reamy BV, Williams PM and Lindsay TJ (2009). Henoch-Schönlein purpura. Am. Fam. Physician 80: 697-704.

Takeshita S, Tokutomi T, Kawase H, Nakatani K, et al. (2001). Elevated serum levels of matrix metalloproteinase-9 (MMP9) in Kawasaki disease. Clin. Exp. Immunol. 125: 340-344. http://dx.doi.org/10.1046/j.1365-2249.2001.01608.x

Yilmaz A, Emre S, Agachan B, Bilge I, et al. (2009). Effect of paraoxonase 1 gene polymorphisms on clinical course of Henoch-Schönlein purpura. J. Nephrol. 22: 726-732.

Zhou TB and Yin SS (2013). Association of matrix metalloproteinase-9 level with the risk of renal involvement for Henoch-Schönlein purpura in children. Ren. Fail. 35: 425-429. http://dx.doi.org/10.3109/0886022X.2012.757826

Zou CC, Zhao ZY, Tang LF and Liang L (2006). Plasma levels of matrix metalloproteinase-9 in Henoch-Schönlein purpura. Scand. J. Rheumatol. 35: 52-55. http://dx.doi.org/10.1080/03009740510026940 